Farkant, J. L. \& Rountree, P. M. (1953). J. gen. Microbiol. 9, 288-292.

\title{
Electron Microscopy of a Staphylococcal Bacteriophage
}

\author{
By J. L. FARRANT \\ Chemical Physics Section, Division of Industrial Chemistry, Commonwealth \\ Scientific and Industrial Research Organization, Melbourne
}

AND PHYLLIS M. ROUNTREE

Fairfax Institute of Pathology, Royal Prince Alfred Hospital, Sydney

SUMMARY: The staphylococcal bacteriophage $3 \mathrm{~A}$ consists of a flat, oblong head, c. $600 \mathrm{~A}$. by $c$. $1000 \mathrm{~A}$., and a long tail, $c .120 \mathrm{~A}$. by $c .2900 \mathrm{~A}$. Fixation with formalin destroys the integrity of the head. Cells infected with the phage release it at the end of the latent period by a process resembling the bursting of a bag. After the phage is released, the empty cell membranes persist for a short time before being dissolved in the medium. Correlation of these findings with turbidity readings and Gram staining of the infected cultures indicate that the turbidity falls only when the shells of the cocci are dissolving.

Electron microscopy has been used extensively to study the morphology of the coli $\mathbf{T}$ series of bacteriophages and the processes of phage adsorption and cellular lysis with these particular host-virus systems. There have been fewer studies of staphylococcal bacteriophages. Wyckoff (1949) published one photograph of the staphylococcus phage $\mathbf{K}$. Included in the paper of Smiles, Welch \& Elford (1948) were unshadowed photographs of cells lysed by phage $\mathrm{K}$ in which the phage particles are arranged radially around the remnants of the cells. Hotchin, Dawson \& Elford (1952) photographed phage $\mathrm{K}$ adsorbed tail first to the cell membranes of staphylococci that had been previously disrupted ultrasonically. This paper is concerned with the staphylococcal phage $\mathbf{3 A}$, originally isolated by Wilson \& Atkinson (1945), the growth characteristics of which have been described elsewhere (Rountree, 1952). The object of the investigation was to study the morphology of the phage and the release of the phage from infected cells.

\section{EXPERIMENTAL}

\section{Preparation of the material}

The material used consisted of:

(1) Phage adsorbed to the surface of heat-killed cells, washed in $0.002 \mathrm{M}$ $\mathrm{CaCl}_{2}$ and twice in distilled water before being placed on the collodion supporting films.

(2) Staphylococci from broth cultures to which sufficient phage had been added to produce infection of all cells. Samples were removed at the end of the one-step growth curve when titrations showed that extracellular phage was increasing. The samples were centrifuged and the cells then fixed in $0 \cdot 2 \%$ $(v / v)$ formalin or in $0.5 \%(w / v)$ osmium tetroxide, and washed twice in water before mounting. 
Unshadowed phage could not be observed satisfactorily, so the preparations were shadowed with uranium at an angle $\tan ^{-1} \frac{1}{4}$. The specimens were examined with an RCA type EMU electron microscope which had been adjusted to minimize all instrumental factors known to detract from the resolution.

\section{RESULTS}

\section{Morphology of the phage and its adsorption}

Pl. 1, fig. 1, shows phage 3A adsorbed to the surface of heat-killed staphylococci. Some unadsorbed particles are present in the field. The particles are characterized by the possession of a flat oblong head, the average dimensions of which are $c .600 \mathrm{~A}$. wide and $c .1000 \mathrm{~A}$. long, and an apparently flexible tail c. $120 \mathrm{~A}$. wide and c. $2900 \mathrm{~A}$. long. The heads contain little electron-scattering material and for this reason are difficult to observe in unshadowed preparations. The collapsed appearance of many of the heads suggests the presence of a limiting membrane around them. The majority of the particles are adsorbed to the surface of the cocci tail first. There is also evidence of the disruption of the coccal cell wall. In this preparation an average of 60-70 particles were adsorbed to each coccus. In preparations with an average of 10 particles per coccus, disruption of the cell wall was not obvious.

\section{Release of phage from infected cells}

Pl. 1, fig. 2, shows cocci fixed in the act of releasing phage. All such cocci that we have observed appear to lyse in one place only, as if the cell wall were torn thus producing a gap through which poured out a stream of phage particles mixed with smaller macro-molecular particles. The smaller particles are similar in size and appearance to those obtained by Hotchin et al. (1952) from ultrasonically disrupted uninfected cells and are probably normal constituents of the cell cytoplasm. In Pl. 1, fig. 2, there is also an intact coccus; the differences between the diameters of the two cocci and the lengths of the shadows cast by them indicate that the release of phage was accompanied by flattening of the coccus. After the phage had been released the walls of the cocci remained for a time as empty shells, a characteristic example of which is shown in Pl. 2, fig. 3. Sometimes one member of a pair of cocci was found intact with the remnants of the other coccus attached to it.

\section{The effect of fixation with formalin}

In Pl. 1, figs. 1 and 2, the material was either unfixed or fixed with osmic acid. In obtaining Pl. 2, fig. 3, formalin was used as the fixative. In such preparations marked alterations in the heads of the phage particles were apparent. The particles appeared mostly either as tails lacking heads Pl. 2, fig. 3, or else the heads, when present, were flattened and hazy in outline Pl. 2, fig. 4. It has been known for many years (Burnet, Keogh \& Lush, 1937) that formalin destroys the infectivity of phage without affecting its antigenicity. The present photographs indicate that the action of the formalin is to rupture the limiting membrane of the phage heads which then disintegrate. 


\section{Correlation of electron microscope appearances with those observed with the optical microscope}

One of the characteristics of phage $\mathbf{3 A}$ is that broth culture in which every coccus has been infected increases in turbidity during the latent period of $50 \mathrm{~min}$.; then follows a period of 15-25 min. during which the turbidity remains stationary or falls only slightly, but during which the infective phage is released from the cocci. Rapid clearing of the cultures takes place only after the phage has been liberated. In certain cases where a low yield of phage/ coccus is obtained the clearing may be prolonged beyond $\mathbf{3} \mathrm{hr}$. Phage $\mathbf{3 A}$ therefore resembles the Staphylococcus muscae phage used by Price (1948, 1949, 1952), and the Bacillus megaterium phage of Northrop (1952) when grown in certain media.

When samples of phage $3 \mathrm{~A}$-infected cultures were removed $75 \mathrm{~min}$. after infection, stained by Gram's method and examined with the light microscope, the appearances observed could be correlated with those seen with the electron microscope. The smears contained large numbers of Gram-positive cocci, some of which were embedded in a matrix of Gram-negative material. The majority of these cocci on careful examination revealed distorted outlines and in a few cases a smear of Gram-negative material was seen apparently emerging from one side of the cell. These distorted cells seem to correspond to the bursting cells of Pl. 1, fig. 2. Also present in the smears were Gram-negative sac-like objects which were sometimes attached to a Gram-positive coccus. Occasionally these sacs had around their edges crescentic areas that were Gram-positive. The sacs appear to correspond to the empty shells of the cocci shown in Pl. 2, figs. 3 and 4. Smears taken later, when clearing of turbidity was proceeding rapidly, showed large amounts of Gram-negative debris and a very few distorted cocci. When clearing was complete, nothing could be seen in the smears.

\section{DISCUSSION}

It has been claimed by Price for the Staph. muscae phage, and by Northrop for a $B$. megaterium phage that these phages may be liberated from infected cells without cellular lysis, although such cells do ultimately lyse. The criteria of cellular lysis used by Price were turbidity readings and microscopic examination of smears stained with methylene blue; Northrop's criterion was turbidimetric. Lwoff \& Gutmann (1950) suggested that Price's results might have been due to lysis of the cocci during the dilution process necessary before phage titration. This suggestion was disposed of by the demonstration of free phage in the supernatants of the infected cultures. Without examination by electron microscopy, claims similar to those of Price and Northrop could have been made for phage $\mathbf{3 A}$. However, phage $\mathbf{3 A}$ is in fact released by the bursting of the infected coccus and the ejection of its contents into the surrounding medium. The shells that remain after the phage is released stain Gram-positive for a short time, gradually lose their Gram positivity and eventually disappear. The turbidity of the cultures, as measured by a photoelectric colorimeter, remains stationary or falls only slightly during the period 
of phage release and falls rapidly only when the shells of the cocci are dissolving. In these cultures, therefore, turbidity is not an adequate criterion of the integrity of the infected cocci.

It would seem that some confusion has been caused by using synonymously the terms 'cellular lysis' and 'phage release'. In most bacteriophage systems these events occur simultaneously and the dramatic disappearance of the bursting cells can be observed with the optical microscope. It has therefore been natural to regard the two events as closely correlated. But with some phages, and in certain media, release of phage may precede complete dissolution of the cells, so that the two events are separated in time. In such cases, however, there is no need to postulate a mechanism of phage release other than the normal bursting of infected cells. In any case, the term 'cellular lysis' is frequently employed to describe types of lysis which occur under conditions other than bacteriophage infection. It might be preferable to use the term 'cellular bursting' for the process of phage release.

It is perhaps significant that the phage systems in which this delayed dissolution of infected cells occurs are those in which the host cells are Gram-positive. Gram-positive cells may possess a cell wall more rigid than that of the Gramnegative organisms in which phage release occurs at the same time as dissolution of the cells. The phenomenon is, however, complex, since different types of media may influence the time of lysis, as may also the use of different but closely related host cells.

Some investigations have suggested (see Bartholomew \& Mittwer, 1952) that the property of Gram-positivity may reside in the cell wall of Gram-positive bacteria, but there is some doubt as to whether the cytoplasm of these cells may or may not be Gram-positive. The Gram-negative character of the material extruded from the $\mathbf{3 A}$-infected cocci, the walls of which were still Gram-positive, suggests that the cytoplasm of these cocci may be Gramnegative. However, the results should be interpreted with caution since the internal organization of these cocci may have been profoundly altered by the process of phage multiplication.

This work was assisted by a grant to one of us (P. M. R.) from the Australian National Health and Medical Research Council.

\section{REFERENCES}

Bartholomew, J. W. \& Mitrwer, T. (1952). The Gram stain. Bact. Rev. 16, 1.

Burnet, F. M., Keogh, E. V. \& LUSH, D. (1937). The immunological reactions of the filtrable viruses. Aust. J. exp. Biol. med. Sci. 15, 231.

Hotchin, J. E., Dawson, I. M. \& Elford, W. J. (1952). The use of empty bacterial membranes in the study of the adsorption of Staphylococcus $K$ phage upon its host. Brit. J. exp. Path. 33, 177.

Lwoff, A. \& GuTManN, A. (1950). Recherches sur un Bacillus megaterium lysogène. Ann. Inst. Pasteur, 78, 711 .

Nortrrop, J. H. (1952). The effect of various culture media on infection, growth, lysis and phage production of $B$. megaterium. J. gen. Physiol. 35, 471.

Price, W. H. (1948). Phage formation in Staphylococcus muscae cultures. II. The release of the virus from the bacterial cell. J. gen. Physiol. 32, 203. 
Price, W. H. (1949). Phage formation in Staphylococcus muscae cultures. V. Further observations on the relationship between virus release and cellular lysis. J. gen. Physiol. 32, 481.

Price, W. H. (1952). Phage formation in Staphylococcus muscae cultures. X. The relationship between virus synthesis, the release of bacterial ribonucleic acid, virus liberation and cellular lysis. J. gen. Physiol. 35, 409.

Rountree, P. M. (1952). Serological studies of the multiplication of a staphylococcal bacteriophage. Aust. J. exp. Biol. med. Sci. 30, 567.

Smules, J., Welch, F. V. \& Elford, W. J. (1948). The influence of antibacterial substances on the interaction of bacteria and bacteriophages. 2. Optical studies of the penicillin effect. J. gen. Microbiol. $2,220$.

Wirson, G. S. \& Atrinson, J. D. (1945). Typing of staphylococei by the bacteriophage method. Lancet, $\mathrm{i}, 647$.

Wyckoff, R. W. (1949). Electron microscopy. New York: Interscience Publishers.

\section{EXPLANATION OF PLATES}

Plate 1

Fig. 1. Staphylococcal phage 3A particles adsorbed on to heat-killed cocci of Staph. aureus.

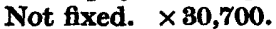

Fig. 2. A burst and an intact cell of Staph. aureus. Fixed with osmium tetroxide. $\times 29,600$.

Prate 2

Fig. 3. An almost empty shell from a burst coccus. Most of the phage particles present lack heads. Fixed with formalin. $\times 30,000$.

Fig. 4. Disintegrating shells from burst cocci. The heads of the phage particles in this field are flattened. Fixed with formalin. $\times 29,400$.

(Received 1 April 1953) 
Journal of General Microbiology, Vol. 9, No. 2

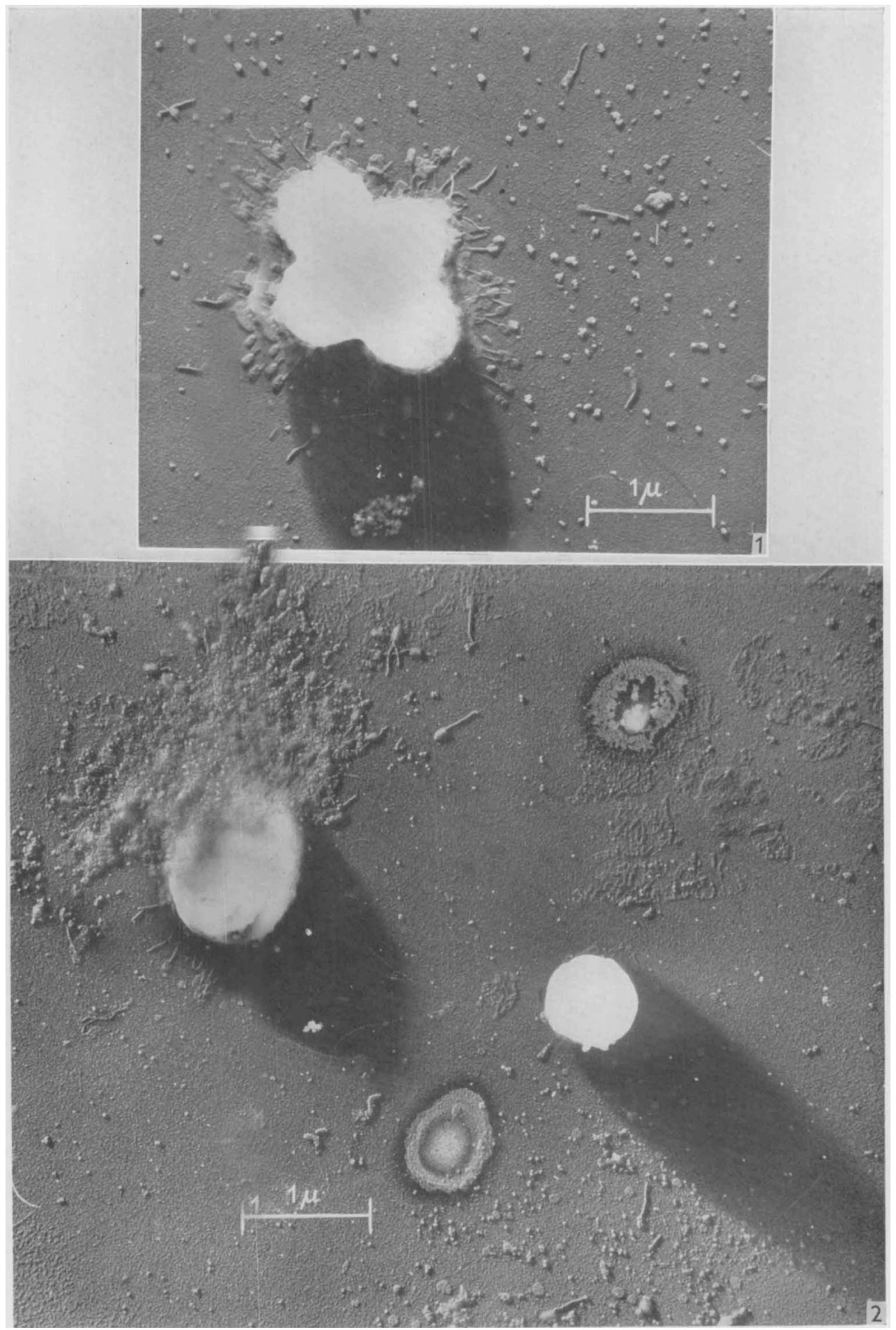

J. L. Farrant \& P. M. Rountree-Electron microscopy of phage 3a. Plate 1 
Journal of General Microbiology, Vol. 9, No. 2
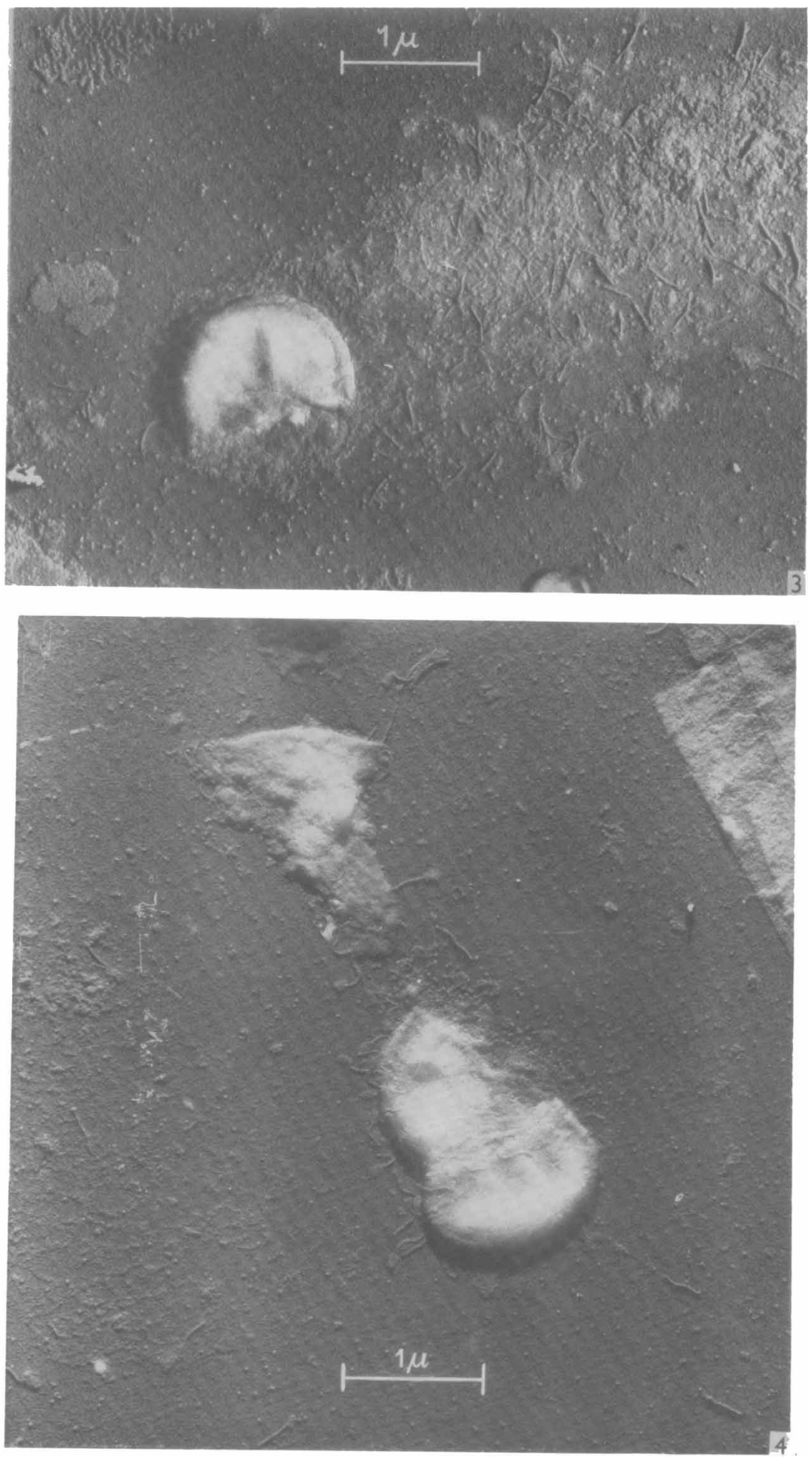

J. L. Farrant \&. P. M. Rountrel-Electron michoscopy of phage 3a. Plate 2 